\title{
Design of Internal Flow Passage of Internal Chip Removal Drill for Suction Type Internal Chip Removal System
}

\section{Meng Wang}

Shenyang Aerospace University

Chengyang Xu ( $\nabla$ xuchengyang1989101@163.com )

Shenyang Aerospace University

Aili Zou

Shenyang Aerospace University

Gongdong Wang

Shenyang Aerospace University

Yiwen wang

Harbin University of Science and Technology

\section{Songyang Yao}

Shenyang Aerospace University

Lei Jin

Shenyang Aerospace University

\section{Research Article}

Keywords: Suction type internal chip removal system, CFRP, chips, internal chip removal drill, internal runner

Posted Date: May 24th, 2021

DOI: https://doi.org/10.21203/rs.3.rs-533495/v1

License: (c) (1) This work is licensed under a Creative Commons Attribution 4.0 International License. Read Full License

Version of Record: A version of this preprint was published at The International Journal of Advanced Manufacturing Technology on January 11th, 2022. See the published version at https://doi.org/10.1007/s00170-021-08430-3. 


\title{
Design of internal flow passage of internal chip removal drill for suction type internal chip removal system
}

\author{
Meng Wang ${ }^{1} \cdot$ Chengyang Xu $^{1} \cdot$ Aili Zou ${ }^{1} \cdot$ Gongdong Wang $^{1} \cdot$ Yiwen wang $^{2} \cdot$ Songyang Yao $^{1} \cdot$ Lei Jin $^{1}$
}

\begin{abstract}
Aiming at the current problem that the cutting chips cannot be automatically recovered in the hole-making process of carbon fiber reinforced resin matrix composites, This article first introduces a new type of drilling chip removal technology system-suction type internal chip removal system, which can timely and effectively discharge the powdery chips generated in CFRP hole processing during cutting; Secondly, in view of the problem of the internal runner design of the internal chip removal drill used in the system, this article conducted the following research: 1) Based on cutting experiments and statistical methods, classify the chips produced in CFRP hole making, and give the chip distribution rules; 2) Secondly, on the basis of fluid mechanics, using FLUENT simulation method, on the basis of defining the center distance and center angle of the inner runner for the design of the internal chip removal drill bit, the center distance and the center angle of the inner runner are given. The influence law of the chip removal center angle and the cross-sectional shape of the internal runner on the chip removal effect of the tool internal runner; 2) Based on fluid mechanics, using FLUENT simulation method, on the basis of defining the center distance of the inner runner and the center angle of the inner runner, the center distance of the inner runner, the center angle and the cross-sectional shape of the inner runner are given to the tool The influence law of the chip removal effect of the internal runner; Finally, a suction type internal chip removal system was built, and the experimental method was used to verify the correctness of the internal runner design of the internal chip removal tool.
\end{abstract}

Keywords Suction type internal chip removal system, CFRP, chips, internal chip removal drill, internal runner

$\triangle$ Chengyang Xu

xuchengyang1989101@163.com

1 College of Aerospace Engineering, Shenyang Aerospace University, Shenyang 110136, China

2 School of Mechanical and Power Engineering, Harbin University of Science and Technology, Harbin 150080, China

\section{Introduction}

Carbon fiber composite materials are widely used in the manufacture of aircraft structural parts, such as rudders, elevators, upper cabin floor beams, and rear panels due to their excellent physical and mechanical properties, such as light weight, high specific strength, high specific rigidity, and good formability [1-3]. Fuselage, horizontal tail and aileron, etc. These structural parts generally need to be mechanically processed before being equipped, among which hole processing is the main one. For example, there are 55,000 assembly holes on only one important CFRP structural part on the Airbus A350 [4-6].

Because CFRP has the characteristics of low interlayer bonding strength, high hardness and good wear resistance, problems such as delamination, burrs and easy wear of processing tools often occur in processing [7-9]. By summarizing the existing research content, it can be known that the generation of delamination defects and burr defects are directly related to tool wear $[10,11]$. Through analysis, it can be known that the main cause of tool wear is the grinding effect between tool-chip-workpiece, Among them, cutting chips act as abrasive particles and are the main reason for aggravating tool wear, in order to reduce the grinding action between the tool-chip-workpiece and improve the service life of the tool and the quality of hole making, first of all, this article introduces a hole-making process method that can effectively remove chips in time during CFRP hole-making process-suction type internal chip removal drilling processing method, during the cutting process, the chips can be recycled to the chip recovery device in real time and effectively through the inner runner of the tool, the inner runner of the outer turning inner chip holder and the related chip removal pipeline. Secondly, on the basis of studying the chip formation mechanism and chip distribution law, the Fluent software is used to study the influence of the position and shape of the runner on the chip evacuation performance of the tool, and finally the design of the internal chip evacuation tool is completed; Finally, a test platform was built to verify the correctness of the above simulation and 
theoretical analysis, and to provide a basis for the subsequent research on the content of the internal chip removal process.

Through the analysis, it can be seen that the calculation of the critical condition of the internal chip removal system and the research on the internal flow channel design of the internal chip removal tool are relatively rare at home and abroad. However, through analysis, it can be known that whether it is the design of the internal flow channel of the internal chip removal tool or the calculation of the critical condition of the internal chip removal system, it is related to the content of gas-solid two-phase fluid mechanics. However, the current research on gas-solid two-phase fluid mechanics has a certain foundation: For example, Dai et al. [12] used Savage's particle dynamics model to study the flow characteristics of high-concentration pulverized coal pneumatic conveying in the elbow, and established a mathematical model for high-concentration pulverized coal pneumatic conveying, The model is also used to conduct mathematical simulation research on the pressure drop and flow distribution law in a vertical turning horizontal $90^{\circ}$ elbow. Li et al. [13] established a mathematical model for the pneumatic conveying of carbon black in elbows by studying the process of pneumatic conveying of carbon black in elbows, At the same time, it also performs numerical simulation analysis on the flow state of carbon black in the elbow, and obtains the relationship between the transportation pressure drop of the carbon black in the elbow and the ratio of the diameter and length of the elbow. Ji et al. [14] based on the research and improvement of the numerical simulation algorithm of the three-dimensional flow field, the porous jump method is used to analyze the distribution of gas phase fluid in the vacuum cleaner, and it is concluded that the main factor that affects the working effect of the vacuum cleaner is the gas flow field. Ottjies et al. [15] conducted a simulation analysis on the movement of solids in a small-caliber horizontal pipe, and obtained the collision of solid particles with the pipe wall under the action of Magnus lift. $\mathrm{Lu}$ et al. [16] conducted experimental and simulation studies on the fluid flow characteristics in the elbow during the pneumatic conveying process, and obtained the axial velocity distribution of the gas-solid two-phase fluid at different positions in the elbow. Sommerfeld et al. [17] conducted a numerical simulation analysis of gas-solid two-phase fluid particles in a circular tube, the particle trajectories of different pipe diameters and different cross-sectional positions of the same pipe diameter are predicted. Dzido et al. [18] took the movement of particles in a vertical pipe as the research object, based on the analysis of the flow characteristics of solid particles in the acceleration zone, combining existing fluid mechanics models, the velocity field and pressure field distribution of spherical particles and non-spherical particles moving in a vertical pipeline are accurately predicted. Based on the above-mentioned literature research, this paper will study the content of the internal flow channel design of the internal chip removal drill bit used in the suction type internal chip removal system in combination with the existing research content of gas-solid two-phase fluid mechanics.

\section{Composition and working principle of suction type internal chip removal system}

The suction type internal chip removal system is composed of the machine tool, CFRP, internal chip removal drill, external rotation internal chip removal tool holder, chip removal pipeline, chip collection device, etc, the structure is shown in Figure 1. Among them, the internal chip removal drill bit and the external rotation internal chip removal tool holder have chip removal channels inside.

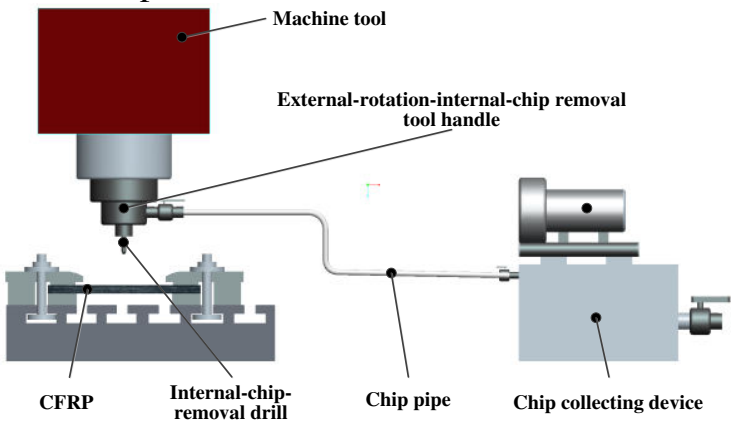

Fig.1 Schematic diagram of suction type internal chip removal drilling system

The function of the system is to discharge the chips generated in the CFRP drilling process through the chip removal channel in real time, reduce manpower and material costs, improve tool life and hole quality, Realize green and efficient processing of CFRP. How the system works, When the machine tool is working, the main shaft drives the inner chip removal drill installed on the outer turning inner chip removal tool holder to perform drilling processing, at the same time, the fan in the chip collection device provides chip suction power (negative pressure), the system uses negative pressure to suck out the chips through the chip suction channel of the drill bit, it is sucked into the chip collection device through the chip removal channel of the drill bit and the outer turning and internal chip removal tool holder with the chip removal channel, then complete the suction type internal chip drilling processing, the system can timely and effectively recover the chips generated during processing, one of the key factors is the internal runner design of the 
internal chip removal tool for the system. Through the analysis, it can be known that the design of the internal flow channel of the internal chip removal tool is related to the chip type and the chip shape distribution area. Therefore, the following is based on experiments to classify the chips generated during CFRP hole making, and study the factors affecting the chip size and the main distribution area after the chips are generated.

\section{Research on chips produced by drilling CFRP}

In order to carry out the internal flow channel design of the internal chip removal tool for the suction type internal chip removal system, this section first adopts experimental methods to classify the chips generated in CFRP drilling; Secondly, the main reasons and proportions of different types of chips are given; Finally, the main factors affecting the chip size and the main distribution area of the chip are analyzed.

\subsection{The CFRP chip classification and formation cause analysis}

(1) Experimental conditions

The CFRP material used in the experiment was provided by Hafei Industry Co., Ltd., with a thickness of $4.5 \mathrm{~mm}$; The drill used in the experiment is a special CFRP drill bit of SD205-7.963-40-8R1-CX31 produced by Seco; The processing equipment used in the experiment is a VDL-1000E CNC milling machine produced by Dalian Machine Tool Factory; The processing parameters used in the experiment are shown in Table 1; The chip size was measured with an ultra-depth-of-field microscope (Keyence VHX-1000).

Table 1 Table of chip experimental processing parameters

\begin{tabular}{cc}
\hline Cutting parameters & Numerical value \\
\hline Speed $n /(r / \mathrm{min})$ & 2000、3000、4000、4500、5000 \\
Feed rate $f /(\mathrm{mm} / \mathrm{min})$ & 50、100、150、200、260 \\
\hline
\end{tabular}

(2) Experimental results and analysis

Carry out the cutting experiment according to the machining parameters shown in Table 2-1, and some of the results obtained from the experiment are shown in Figure 2;

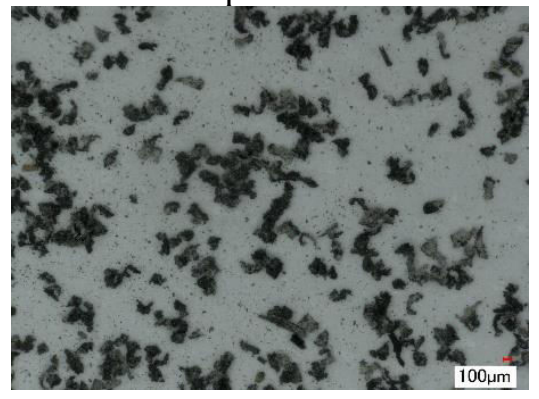

Fig.2 Cutting chips for hole making with CFRP

Through the observation and analysis of the chips obtained from the experiment, it is concluded that, strip-shaped chips, micro-circular chips, rice-shaped chips, fiber pull-out chips, and $\mathrm{C}$-shaped chips are produced in CFRP drilling. Chips with a maximum length of less than $100 \mu \mathrm{m}$ are called rice chips.

\subsection{Analysis of the causes of different types of cutting}

Analysis of the causes of rice chips, In the CFRP drilling process, the material will be squeezed under the action of the shear force of the drill chisel edge and will be misaligned with the cutting edge to form irregularly shaped and tiny crushed and crushed chips (ie, rice-shaped chips) ) As shown in Figure 3.

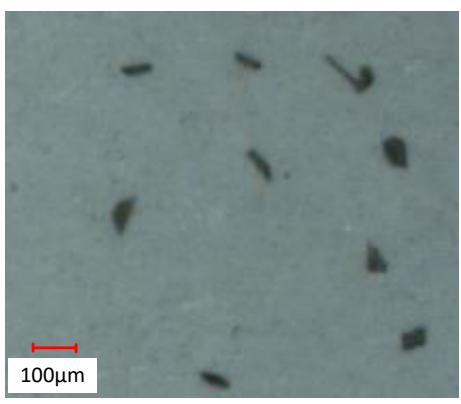

Fig.3 Rice chip

Analysis of the causes of strip chips and micro-circular chips, During the drilling process, the feed amount is fixed, that is, the distance that the chip cutting edge of the drill moves in a unit time is a certain amount, that is, the thickness of the chip is determined. The cutting edge is inclined relative to the material to be cut and there is an uncertain torque effect, so the material to be cut is easy to fail and fracture, and there will be no chips at both ends, that is, strip-shaped chips and micro-circular chips will be produced. , As shown in Figures 4 and 5. Through further analysis, it can be seen that the length of the chip depends on the length of the cutting edge, and the thickness of the chip has a great relationship with the feed rate.

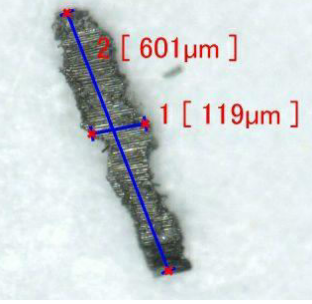

Fig.4 Strip chip

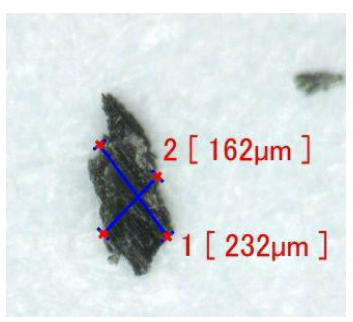

Fig.5 Microcircular chip
Analysis of the causes of C-shaped chips and fiber pull-out chips, Due to the poor thermal conductivity of carbon fiber composite materials, as the processing progresses, the 
accumulation of heat will increase the processing temperature. When the temperature reaches a certain temperature, due to the torque, the strip-shaped chips will become $\mathrm{C}$-shaped with a certain bending angle. Chips, as shown in Figure 6. At the same time, the temperature increase will soften the CFRP material matrix, which will reduce the bonding force between the fiber and the resin, which will cause the fiber pull phenomenon during the cutting process to form chips with burrs or tearing defects, as shown in Figure 7 shown.

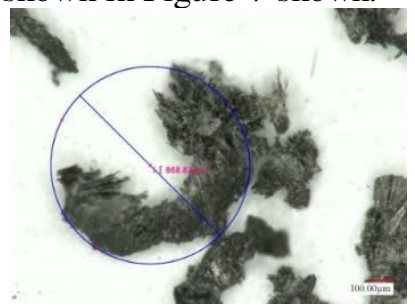

Fig.6 C chip

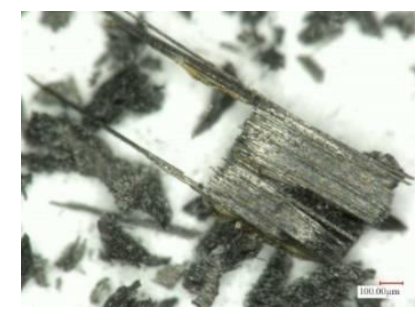

Fig.7 Fiber pull-out chip

\subsection{Proportion of different types of chips}

In order to further understand the proportion of different types of chips during CFRP drilling, 5 groups of experimental chips were randomly selected, and the method of ultra-depth-of-field microscope observation was used to calculate the chip shape and quantity. The statistical results are shown in Table 2.

Table 2 Proportion of chips with different shapes

\begin{tabular}{cccccc}
\hline Group number & 1 & 2 & 3 & 4 & 5 \\
Proportion of types (to) & & & & & \multirow{2}{*}{ (t) } \\
\hline strip-shaped chips & 73.5 & 75.3 & 69.7 & 79.6 & 71.6 \\
micro-circular chips & 23.5 & 21.9 & 25.3 & 18.5 & 22.8 \\
C-shaped chips & 2.9 & 2.8 & 4 & 1.9 & 5.6 \\
fiber pull-out chips & 0 & 0 & 1 & 0 & 0 \\
\hline
\end{tabular}

From the chip statistics in the table above, it can be seen that strip-shaped chips account for about $74 \%$ of the total, followed by micro-circular chips about $22 \%$. The smallest proportion is $\mathrm{C}$-shaped chips, and there are almost no fiber pull-out chips. rice-shaped chips or their type chips account for about $2 \%$.

\subsection{Analysis of the influencing factors of chip size and the law of chip distribution}

By observing the chips obtained in the above experiment through the ultra-depth of field, the relationship curve between the cutting parameters and the equivalent diameter of the chip (The definition of the equivalent chip diameter is defined in the literature [19]) is shown in Figure 8.

From the analysis of Figure 8, it can be seen that: (1) When the speed is constant, the equivalent diameter of the chips obtained by hole making increases with the increase of the feed; (2) When the feed amount is $50(\mathrm{~mm} / \mathrm{min})$ 、 $100(\mathrm{~mm} / \mathrm{min})$ and $200(\mathrm{~mm} / \mathrm{min})$, the equivalent diameter of the chips obtained by hole making increases with the increase of the speed; When the feed rate is 150 $(\mathrm{mm} / \mathrm{min})$, the chip diameter obtained from hole-making processing increases first and then decreases with the increase in speed; When the feed rate is $260(\mathrm{~mm} / \mathrm{min})$, the equivalent diameter of the chips obtained from hole-making processing will first decrease and then increase with the increase of the speed; Analyze the causes of the above phenomenon: When the speed is constant, the feed rate increases, and the distance moved by the cutting edge of the drill bit per unit time will increase, which will lead to an increase in the equivalent chip diameter; (3) Through analysis, we can know the range $0.2 \mathrm{~mm} \leq \mathrm{d}_{\mathrm{s}} \leq 1.8 \mathrm{~mm}$ of the equivalent chip diameter obtained in this experiment; (4) After the experiment, the measurement shows that when the vertical distance between the drill tip and the upper surface of the CFRP is 14-18 (mm), the angle between the axis of the drill bit and the chip edge line (Definition: The connecting line between the drill tip and the edge of the flying chip is the chip edge line) is $12^{\circ}-20^{\circ}$, this measurement The results can provide a reference for the subsequent determination and simulation of the chip domain.

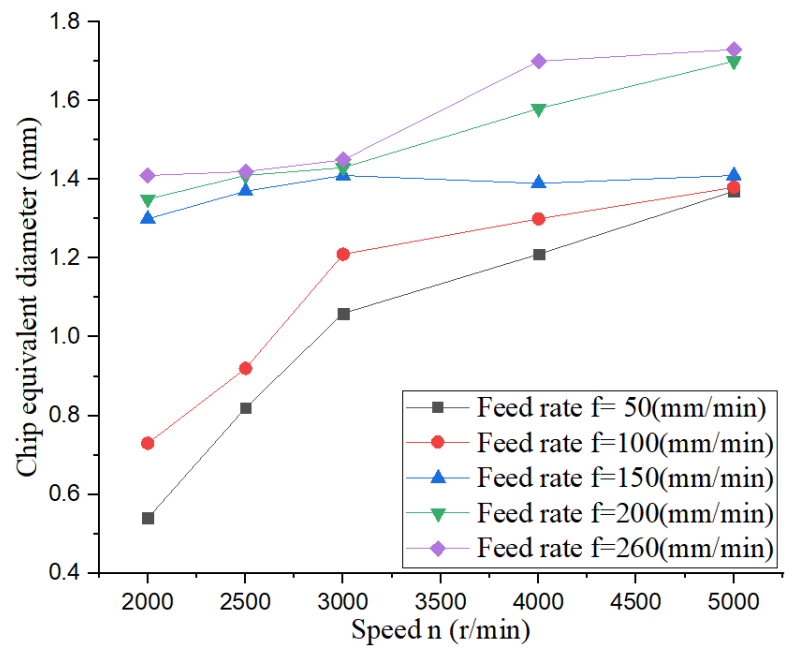

Fig.8 Relation curve of rotation, feed rate and chip diameter

\section{Design of the internal runner structure of the tool}

According to the working principle of the suction type internal chip removal system, the working power (negative pressure) of the system is provided by the fan on the chip collecting box. It is the power source for the system to suck the chips, and the medium used is air. The main principle of chip flow in the drill body is that the system uses a fan to form a negative pressure flow field in the chip removal 
channel and the chip suction channel of the drill body to recover the chips generated in the drilling process. The key to whether the chips can be discharged effectively in time under the action of the negative pressure flow field is the distribution of the pressure field and the velocity field in the flow channel. Therefore, this article adopts the Fluent simulation method, To study the influence of the position and shape of the inner runner of the tool on the chip removal quality of the inner runner and on the basis of this research, the internal runner design of the tool is completed.

\subsection{Physical properties of research object}

In order to ensure the correctness of the simulation analysis, the physical properties of the two research objects, the gas phase and the solid phase, must be given according to the actual situation. Therefore, the physical properties of the two objects will be introduced below.

The physical properties of the gas: This article uses the gas phase medium commonly used in engineering as the research fluid medium, that is, room temperature air under standard pressure. The parameters are shown in Table 3.

Table 3 Physical characteristics of air

\begin{tabular}{cc}
\hline Physical characteristics & Numerical value \\
\hline Density $\left(\mathrm{kg} / \mathrm{m}^{3}\right)$ & 1.205 \\
Viscosity $\left(\mathrm{N} \cdot \mathrm{S} / \mathrm{m}^{2}\right)$ & $1.8 \times 10^{-5}$ \\
\hline
\end{tabular}

The physical properties of the chips: The chips used in this study are obtained from the experiment in Section 2, the equivalent diameter of the chips used in the simulation is given in Section 2, and the equivalent method of chip diameter is known from the literature [19]. The specific physical properties of the chips are shown in Table 4.

Table 4 Physical properties of chips

\begin{tabular}{cc}
\hline Solid phase & CFRP chip partic les \\
\hline Chip density $\quad \rho_{\mathrm{s}} /\left(\mathrm{kg} / \mathrm{m}^{3}\right)$ & 1810 \\
Chip diameter $\quad d_{s} /(\mathrm{mm})$ & 1.8 \\
Specific heat $\left(\mathrm{Cal} /\left(\mathrm{g} \cdot{ }^{\circ} \mathrm{C}\right)\right)$ & 0.18 \\
Chemical composition & $96 \% \mathrm{C}$ \\
\hline
\end{tabular}

\subsection{Fluid domain modeling and meshing for simulation}

(1) Fluid domain modeling for simulation

When using gas-solid two-phase fluid mechanics to analyze actual engineering problems, it is first necessary to establish a flow domain model. The main content of this paper is the chip removal performance of the internal flow channel of the drill bit in the internal chip removal system, so only the internal flow channel model and the chip fluid domain model for chip removal of the drill bit can be established. Because the built model has complex three-dimensional surfaces, this paper uses Pro/E software to model the internal chip removal channel and the chip removal fluid domain. Based on the above analysis and actual processing conditions, an internal chip removal channel model and a chip removal fluid domain model with a Y-shaped flow channel are established, as shown in Figure 9.

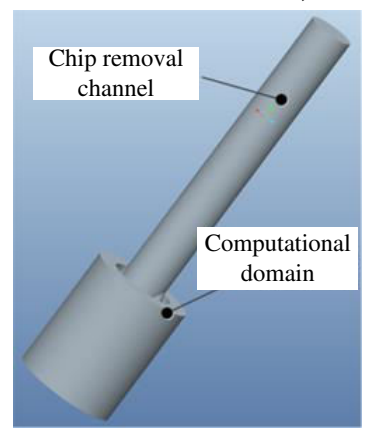

Fig.9 Chip removal fluid domain model

\section{(2) Mesh division}

This paper uses the structured hybrid grid (TGrid) to divide the chip removal fluid domain model, and apply the size function to the position where the chip removal channel and the chip suction channel in the internal chip removal drill are connected. After the mesh is divided, the total number of grid nodes is about 1 million. The result of the mesh quality check through the software is that the result shows that this grid division can achieve high-efficiency numerical calculations, using this grid for simulation can get high-quality numerical simulation results. The structured hybrid meshing model is shown in Figure 10.

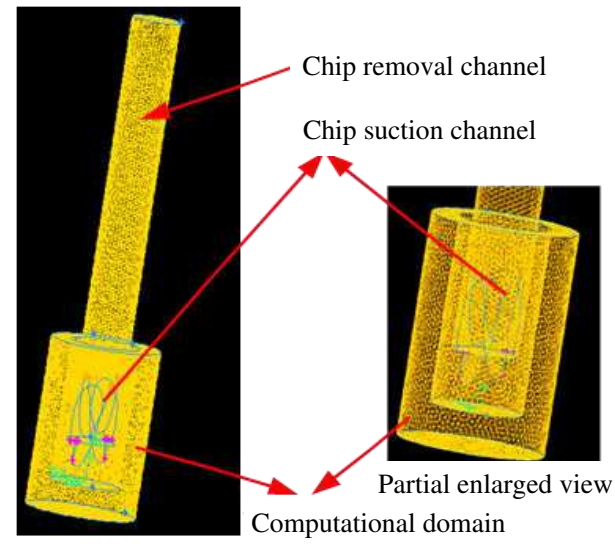

Fig.10 Grid of inner flow channel and fluid domain

(3) Boundary condition setting for simulation 
Use the second-order implicit propulsion method to simulate the turbulence model established by the RNGk $-\varepsilon$ simulation method, the wall condition is set as a standard wall function, set the inlet of the flow channel as a pressure inlet, and set the outlet of the flow channel as a pressure outlet, According to the above settings to describe the transient characteristics of the fluid domain during the internal chip removal drilling process, at the same time, no-slip conditions are applied to the rotating domains such as the calculation domain and the rotating wall of the flow channel. In order to ensure the authenticity of the CFRP internal chip removal drilling process simulation and to track the trajectory of the CFRP chip particles in the chip removal channel, the DPM model in Fluent is used to simulate it to complete the research on the chip flow in the flow channel of the tool and the quality of chip removal.

In order to realize the trajectory tracking of the CFRP particles using the DPM model, the chip generation quality is calculated according to the instantaneous chip flow formula 1 during the analysis.

$$
Q=\rho_{s} \pi\left[\left(\frac{D}{2}+a_{p}\right)^{2}-\left(\frac{D}{2}\right)^{2}\right] f n
$$

\subsection{Optimized simulation of the flow channel structure in the drill bit}

On the basis of the above theoretical analysis and simulation settings, Fluent software is used to optimize the simulation of the internal flow channel structure of the internal chip removal drill. Definition: The distance between the top of the cutter body and the intersection of the center line of the chip suction flow channel and the center line of the chip discharge channel is the center distance of the flow channel, represented by $h$, as shown in Figure 11; The angle between the centerline of the chip suction channel and the centerline of the chip discharge channel is defined as the center angle of the channel, which is represented by $\delta$, as shown in Figure 11. In order to design the flow channel in the drill bit: First of all, combined with the chip distribution

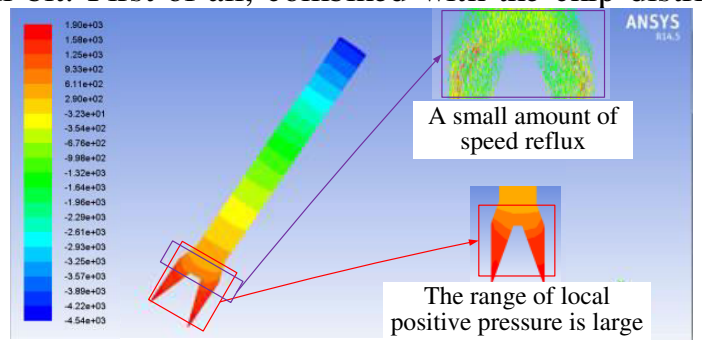

a ) $h=14 \mathrm{~mm}$ area obtained in the experiment, the range of the center distance of the runner and the center angle of the runner is given as shown in Table 4-3; Secondly, through calculation, it can be known that the volume of chips discharged per unit time accounts for about $20 \%$ of the volume of the flow channel in the entire drill bit. The experimental coefficient used in this section is 1.6; Finally, according to the literature [20], when the center angle of the runner is $12^{\circ} \sim 20^{\circ}$, the negative pressure required for chip removal of the system is $9 \mathrm{KPa}$. The processing parameters used in the simulation are shown in Table 5.

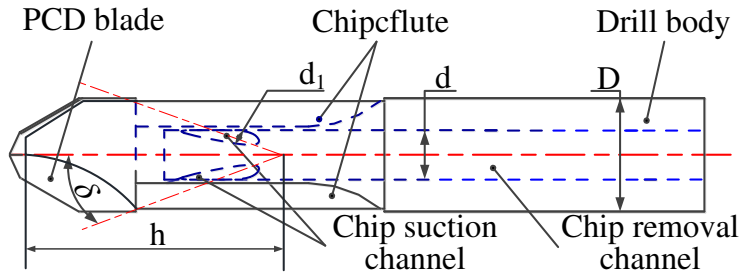

Fig.11 Drill bit inner channel structure

Table 5 Simulation parameters

\begin{tabular}{|c|c|}
\hline Parameter name & Numerical value \\
\hline Speed $n /(r / \min )$ & 3000 \\
\hline Feed rate $f /(\mathrm{mm} / \mathrm{min})$ & 200 \\
\hline $\begin{array}{l}\text { The channel center distance } \\
\qquad h /(\mathrm{mm})\end{array}$ & $14 、 15,16 、 17,18$ \\
\hline $\begin{array}{l}\text { The channel center angle } \\
\qquad \delta /\left({ }^{\circ}\right)\end{array}$ & $12 、 14,16 、 18,20$ \\
\hline
\end{tabular}

(1) The simulation analysis of the center distance of the inner runner center of the inner chip removal bit

Select the drill bit diameter $D=8 \mathrm{~mm}$, the chip suction channel diameter $d_{1}=2.0 \mathrm{~mm}$, the chip removal channel diameter $d=4.0 \mathrm{~mm}$, the channel center angle $\delta=20^{\circ}$, and the chip removal negative pressure $9 \mathrm{Kpa}$, the simulation analysis of the influence of the center distance of the internal chip removal drill bit runner on the chip removal effect of the runner is carried out, and the simulation result is shown in Figure 12.

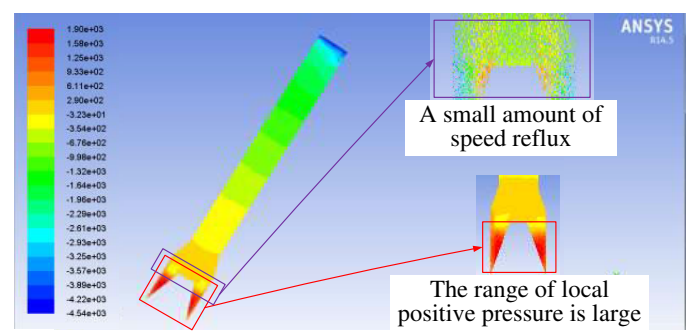

b ) $h=15 \mathrm{~mm}$ 


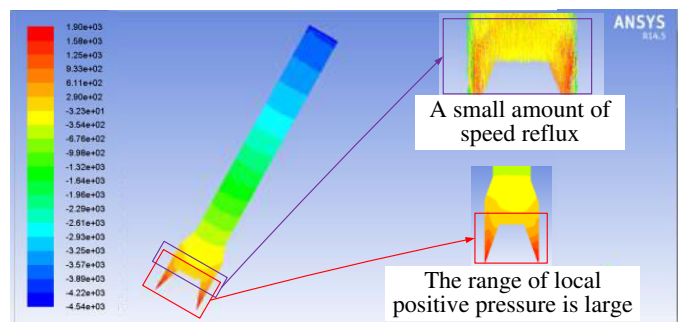

c ) $h=16 \mathrm{~mm}$

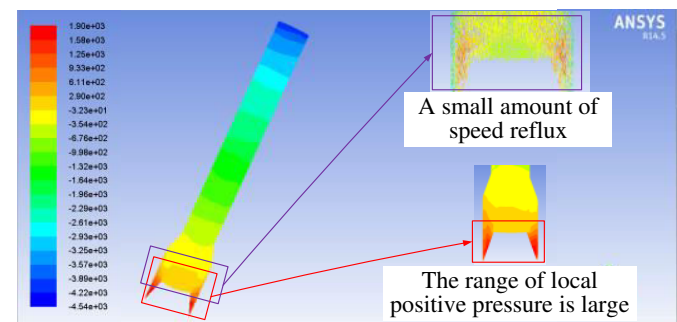

d ) $h=17 \mathrm{~mm}$

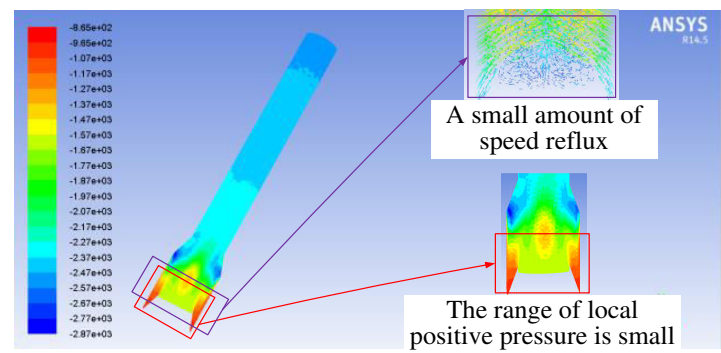

e ) $h=18 \mathrm{~mm}$

Fig.12 Simulation analysis of the influence of the center distance of the runner on the chip removal effect of the runner

By analyzing the simulation results shown in Figure 12 inferred: 1) When using different flow channel center distances for internal flow channel chip removal simulation, local positive pressure will appear in the drill bit flow channel, which will affect the normal discharge of chips; 2) As the center distance of the runners increases, the range of local positive pressure in the runners in the drill bit gradually decreases; 3) When the flow channel center distance is $18 \mathrm{~mm}$, the local positive pressure range of the flow channel in the drill bit reaches the minimum value, and the pressure field distribution meets the chip removal requirements of this article.

In order to further verify that when the flow channel center distance is $18 \mathrm{~mm}$, the pressure field distribution of the flow channel in the drill bit meets the chip removal requirements of this article, further analysis of the simulation results obtained in Figure 12e) shows that : 1) The pressure value of the chip discharge channel is gradually decreasing along the chip discharge direction, which is in line with the normal pressure drop trend; 2) The pressure field distribution at the

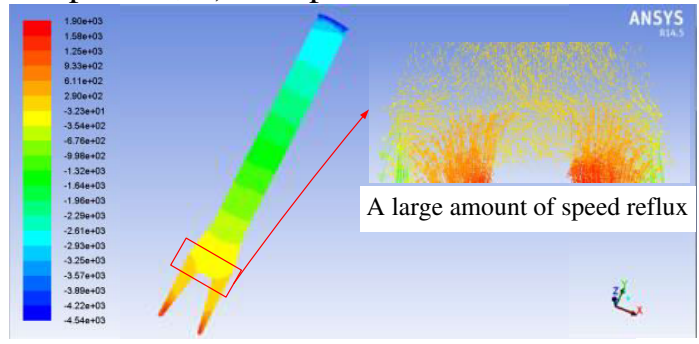

a) $\delta=12^{\circ}$ position of the chip suction channel is relatively balanced, which can ensure the smooth discharge of the chips; 3 ) There is a small amount of pressure vortex around the flow field of the chip suction channel, which may cause pressure changes, but does not affect the normal discharge of chips. In summary, when the flow channel center distance is $\mathrm{h}=18 \mathrm{~mm}$, the chip removal pressure distribution in the chip removal channel of the internal chip removal drill designed in this paper can enable the chips generated in the cutting process to be discharged smoothly.

(2) Simulation analysis of the center angle of the inner runner of the internal chip removal bit

Choose drill diameter $D=8 \mathrm{~mm}$, chip suction channel diameter $d_{1}=2.0 \mathrm{~mm}$, chip removal channel diameter $d=4.0 \mathrm{~mm}$, channel center distance $\mathrm{h}=18 \mathrm{~mm}$, chip removal negative pressure $9 \mathrm{KPa}$, The simulation analysis of the influence of the center angle of the internal chip removal bit on the chip removal effect of the channel is carried out. The simulation results are shown in Figure 13.

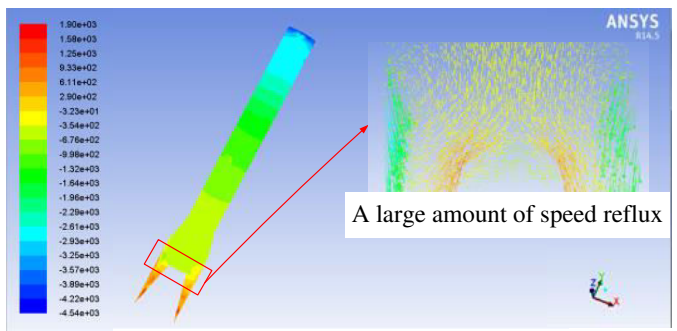

b ) $\delta=14^{\circ}$ 


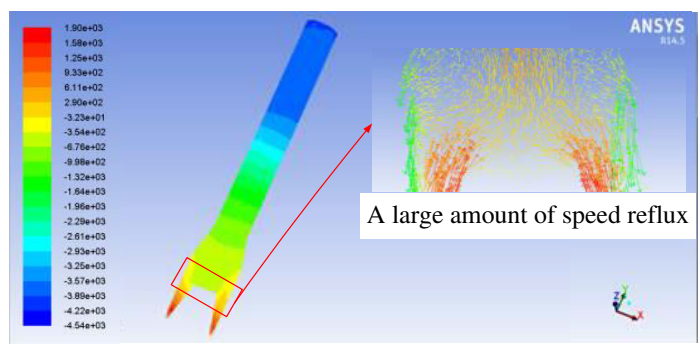

c ) $\delta=16^{\circ}$

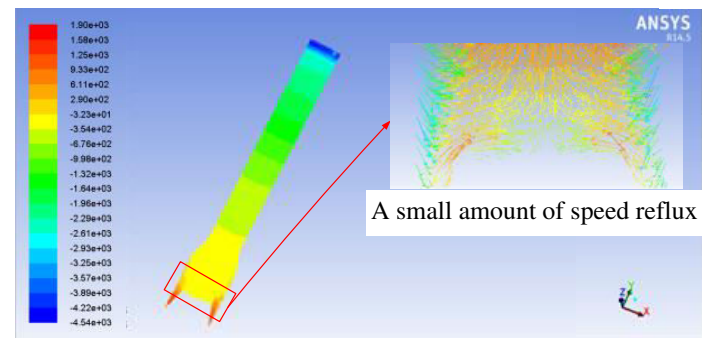

d ) $\delta=18^{\circ}$

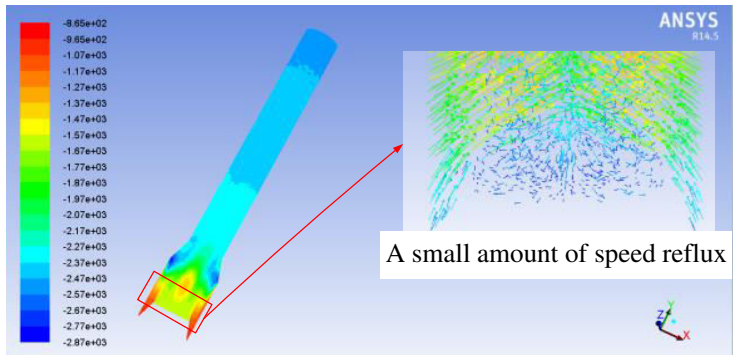

e ) $\delta=20^{\circ}$

Fig.13 Simulation analysis of the influence of the center distance of the runner on the chip removal effect of the runner

By analyzing the simulation results shown in Figure 13 inferred: 1) When using different channel center angles for internal channel chip removal simulation, there will be a local backflow phenomenon in the flow channel of the drill bit, which will affect the normal discharge of chips; 2) Through further analysis of the scope of the local backflow phenomenon, it can be seen that as the center angle of the runner increases, the area where the local backflow phenomenon occurs in the runner in the drill bit gradually decreases; 3) When the flow channel center angle is $20^{\circ}$, the flow channel velocity backflow phenomenon in the drill bit reaches the minimum value, and the velocity field distribution meets the chip removal requirements of this article.

(3) Simulation analysis of the internal flow channel shape of the internal chip removal bit

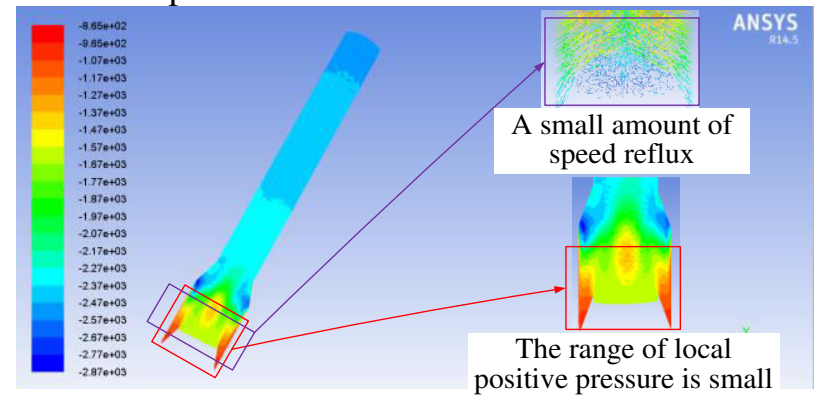

a ) Circular
Through the above simulation content, the design of the center distance of the bit runner center and the center angle of the runner can be completed, but the influence of the inner runner shape of the drill bit on the chip removal effect of the system is not considered, so the following simulation method is used to study the influence of the inner runner shape on the system The effect of chip removal.

Select drill bit diameter $D=8 \mathrm{~mm}$, chip suction channel diameter $d_{1}=2.0 \mathrm{~mm}$, chip removal channel diameter $d=4.0 \mathrm{~mm}$, channel center distance $\mathrm{h}=18 \mathrm{~mm}$, channel center angle $\delta=20^{\circ}$, chip removal negative pressure $9 \mathrm{KPa}$, The simulation analysis of the flow channel shape of the internal chip removal bit on the chip removal effect of the flow channel is carried out. The three flow channels used in the simulation have the same area, and the results are shown in Figure 14.

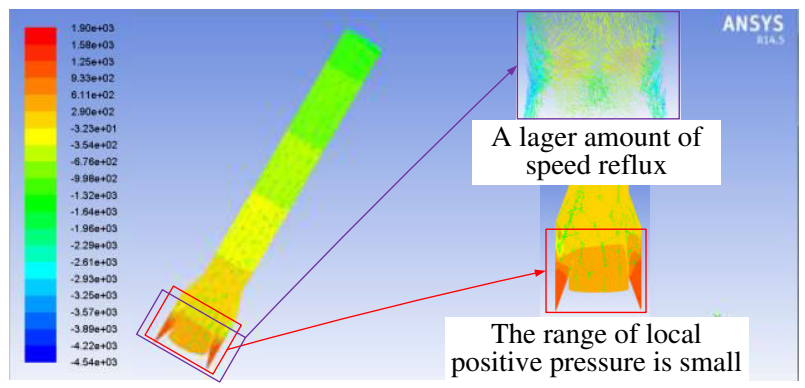

b ) Ellipse 


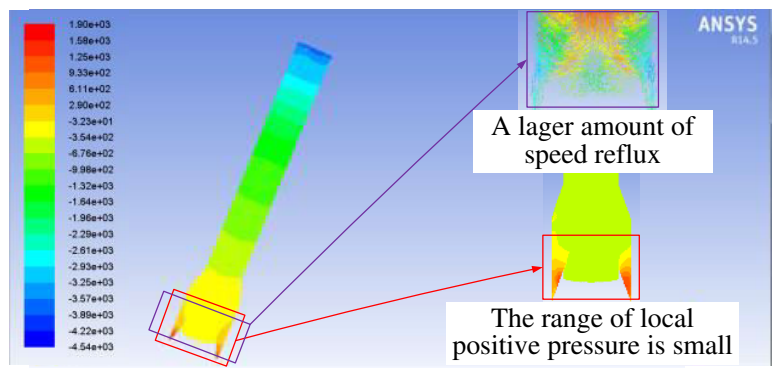

c ) Square

Fig.14 Simulation analysis of the influence of the shape of the flow channel on the chip removal effect of the flow channel

By analyzing the simulation results shown in Figure 14 inferred: The speed backflow phenomenon and local positive pressure of the circular chip removal channel are better than those of the other two shapes of chip removal channels (that is, when the circular structure of the chip removal channel is used for chip removal, the chip removal effect is better than other types). Analyze the reasons for the above phenomenon: in the case of a certain area of the chip removal channel, the circular channel has the shortest perimeter, the equivalent diameter at this time, the maximum Reynolds number in the pipe, that is, the wind speed of the pipe section is the most uniform, and the chips are passing through When the section is cross-sectioned, the passage area that is pulled by uneven wind speed is the smallest, which is most conducive to the normal discharge of chips.

\section{Experimental verification}

\subsection{Experimental conditions}

In order to verify the correctness of the simulation analysis of the chip removal drill in the previous article and study the chip removal effect of the internal chip removal drill, it is necessary to build a suction type internal chip removal system. According to the above research content, build the suction type internal chip removal system as shown in Figure 15, which includes the machine tool (SYIL-X4), the internal chip removal drill (as shown in Figure 16, see the reference for the design of the bit part [20] ), outer turning inner chip removal tool holder, chip collection device, control system, chip removal pipeline (Dongguan Keweidi Pipe Industry Co., Ltd.) and CFRP. In order to facilitate the analysis of the experimental results, the real-time chip recovery rate is used to measure the chip removal effect (the real-time chip recovery rate described in this article is when 10 holes are processed under the same parameter, the actual recovered chip quality and the total quality of the chip produced by the hole-making process ratio).

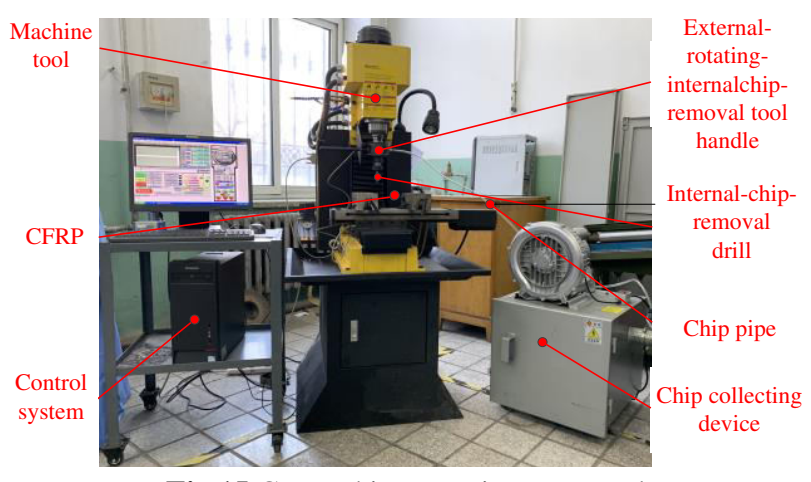

Fig.15 CFRP chip removing test stand

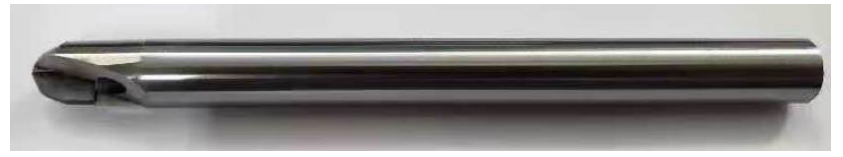

Fig.16 PCD inner chip removing drill

\subsection{Experimental results and analysis}

In order to prove the chip removal effect of the internal flow channel of the internal chip removal drill used in the suction type internal chip removal system, the chip removal situation of the industrial vacuum cleaner with the external chip removal device used in the general factory is now compared and analyzed.

Chip parameters $n=3000 \mathrm{r} / \mathrm{min}$ and $f=200 \mathrm{r} / \mathrm{min}$, chip removal negative pressure $P=9 \mathrm{KPa}$ of the internal chip removal system, and the tool is an internal chip removal drill designed and manufactured by ourselves.

The external chip removal device adopts a model 202 industrial vacuum cleaner produced by a certain manufacturer, and its working negative pressure is $P \geq 17 \mathrm{KPa}$.

Through the analysis of the experimental structure, the real-time recovery rate of the chips of the inner chip conveyor is about $93 \%$, and the real-time recovery rate of the chips of the outer chip conveyor is about $85 \%$.

Through the above experimental analysis, it can be known that when the internal runner designed in this paper is used 
for drilling and chip removal, both the chip removal quality and the chip removal effect are better than the external chip removal device industrial vacuum cleaner, it also further illustrates the correctness of the internal flow channel of the internal chip removal drill designed in this paper.

\section{Conclusion}

(1) Through the combination of experiment and theoretical analysis, it is concluded that various types of chips, such as strip chips, micro-circular chips, rice chips, fiber pull-out chips, and C-shaped chips, will be generated during CFRP hole making. The chip distribution law during hole making is given, that is, when the vertical distance between the drill tip and the upper surface of the CFRP is $14-18(\mathrm{~mm})$, the angle between the drill bit axis and the chip edge line is $12^{\circ}-20^{\circ}$.

(2) On the basis of defining the center angle and center distance of the inner runner of the internal chip removal drill, through simulation analysis inferred: 1) Within the given parameter range, with the increase of the flow channel center distance, the range of the local positive pressure of the flow channel in the drill bit gradually decreases; 2) Within the given parameter range, as the center angle of the runner increases, the area where the local backflow phenomenon occurs in the runner in the drill bit gradually decreases; 3 ) Within the given parameter range, the velocity recirculation phenomenon and local positive pressure phenomenon of the circular chip removal channel are better than the other two shapes of chip removal channel (that is, the circular structure of the chip removal channel is used for removal. When chipping, the chip removal effect is better than the other two shapes of chip removal channel).

(3) Building a suction type internal chip removal system. It is obtained through experiments that when the internal runner designed in this paper is used for drilling and chip removal, both the chip removal quality and the chip removal effect are better than the external chip removal device industrial vacuum cleaner.

Funding information Thanks to The National Defense Science and Technology Innovation Special Zone Fund Project (208052020162) and The Shenyang Aerospace University Expo project (120421007)

Author Contributions Theoretical analysis and model construction were completed by Xu Chengyang and Wang Yiwen; The simulation analysis is completed by $\mathrm{Xu}$ Chengyang and Wang Meng; The experimental design and analysis were completed by $\mathrm{Xu}$ Chengyang , Wang GongDong and Zhou Aili; The thesis was written by $\mathrm{Xu}$ Chengyang , Yao Songyang and Jinlei; The supervision and optimization of the paper were completed by Wang Yiwen and Zou Aili.

Data availability All data generated or analyzed during this study are included in this published article.

\section{Compliance with ethical standards}

Competing interests The authors declare that they have no conflict of interest.

Ethical approval Not applicable

Consent to participate Not applicable

Consent to publish The authors consent to publish this article

\section{References}

1. Wang FJ, Qian BW, Jia ZY, Fu R, Cheng D. Secondary cutting edge wear of one-shot drill bit in drilling CFRP and its impact on hole quality[J]. Compos Struct, 2019, 15(178): 341-352.

2. Perez JLM, Royer R, Merson E, Lockwood A, sabino AS, Marshall MB. Influence of workpiece constituents and cutting speed on the cutting forces developed in the conventional drilling of CFRP composites[J]. Compos Struct, 2016, 140: 621-629.

3. Jia ZY, Bi GJ, Wang FJ, Wang XN, Zhang BY. The research of machining mechanism of carbon fiber reinforced plastic $[\mathrm{J}]$. J Mech Eng, 2018, 23(54): 199-208.

4. Wang FJ, Qian BW, Cheng D, Jia ZY, Fu R, Yin JW. Wear of one-shot drill bit in drilling CFRP and novel method for tool wear reduction [J]. J Mech Eng, 2018, 54(15): 171-179.

5. Xia T, Kaynak Y, Arvin C, Jawahir IS. Cryogenic cooling-induced process performance and surface integrity in drilling CFRP composite material[J]. Int J Adv Manuf Technol, 2016, 82(1-4): 605-616.

6. Liu SN, Qi ZC, LI Y, Meng QX. On full life-cycle instantaneous force predicting when drilling CFRP-metal stacks[J]. Int J Adv Manuf Technol, 2017, 88(1-4): 651-661.

7. Jia ZY, Fu R, Niu B, Qian BW, Bai Y, Wang FJ. Novel drill structure for damage reduction in drilling CFRP composites[J]. Int J Mach Tool Manu, 2016, 110: 55-65.

8. Yang HJ, Chen Y, Xu JH, Ladonne M, Lonfier J, Fu YC. Tool wear mechanism in low-frequency vibration-assisted drilling of CFRP/Ti stacks and its individual layer[J]. Int $\mathrm{J}$ Adv Manuf Technol, 2019, 104 (5-8): 2539-2551.

9. Wang XC, Shen XT, Zeng C, Sun FH. Combined influences of tool shape and as-deposited diamond film on cutting performance of drills for CFRP machining[J]. Surf Coat Tech 2018, 347(15): 390-397.

10. Girot F, Dau F, Gutierrez OM. New analytical model for delamination of CFRP during drilling[J]. J Mater Process Tech, 2017, 240: 332-343.

11. Gaugel S, Sripathy P, Haeger A, Meinhard D, Bernthaler T, Lissek F, Kaufeld M, Knoblauch V, schneider G. A comparative study on tool wear and laminate damage in drilling of 
carbon-fiber reinforced polymers (CFRP) $[\mathrm{J}]$. Compos Struct, 2016, 155(1): 173-183.

12. Dai QX, Ding XY, Xu HF, Liu CH, JuTH. Numerical simulation of conveying characteristics of dense phase pulverized coal in bend pipe[J]. Journal of Iron and Steel Research, 2020, 32(5): 377-385.

13. Li ZH, Li XC, Liu GM. Numerical simulation and analys is on pneumatic conveying of carbon black in bend pipeline $[\mathrm{J}]$. China Rubber Industry, 2016, 62(8): 495-498.

14. Ji SC. Numerical simulation of airflow distribution in electrostatic precipitator [J]. Chinese Journal of Environmental Engineering 2016, 10(4): 1959-1960.

15. Ottjes JA. Digital simulation of pneumatic particle transport[J]. Chemical Engineering Science, 2001, 33(6): 783-786.

16. Lu Y, Tong ZB, Glass DH, Easson WJ, Ye M. Experimental and numerical study of particle velocity distribution in the vertical pipe after a $90^{\circ}$ elbow[J]. Powder Technol, 2017, 314: 500-509.

17. Sommerfeld M, Lain S. Parameters influencing dilute-phase pneumatic conveying through pipe systems: A computational study by the Euler/Lagrange approach[J]. Can J Chem Eng, 2015, 93(1): 1-17.

18. Dzido G, Palica M, Raczek J. Investigations of the acceleration region in the vertical pneumatic conveying[J]. Powder Technol, 2002, 127(2): 99-106.

19. Xu CY, Wang YW, Xu JZ, Liu XL (2018) Calculation of negative-pressure chip in suction-type internal chip removal system and analysis of influencing factors. Int $\mathbf{J}$ Adv Manuf Technol 99(1-4): 201-209.

20. Wang YW, Xu CY, Xu JZ, Liu XL (2019) Simulation analys is and experimental study on chip removal conditions of internal chip removal bits for CFRP machining. J Mech Eng 55(5):223-231. 


\section{Figures}

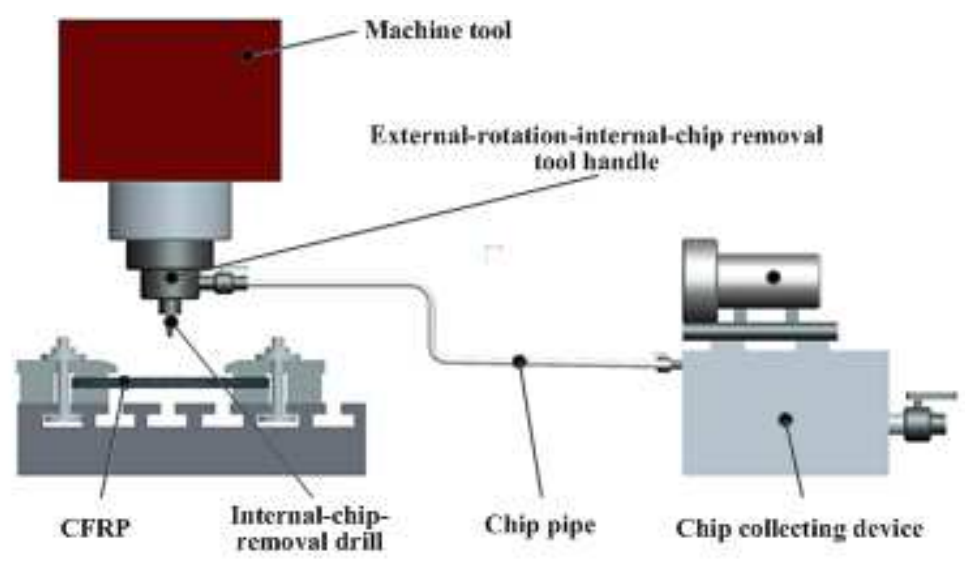

\section{Figure 1}

Schematic diagram of suction type internal chip removal drilling system

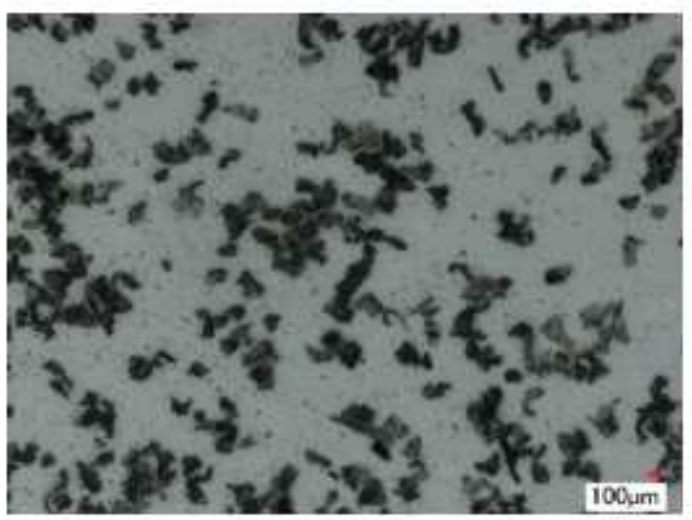

Figure 2

Cutting chips for hole making with CFRP

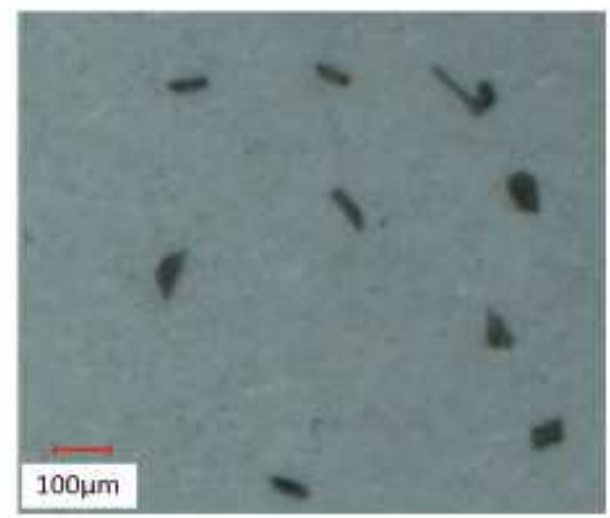

\section{Figure 3}

Rice chip 


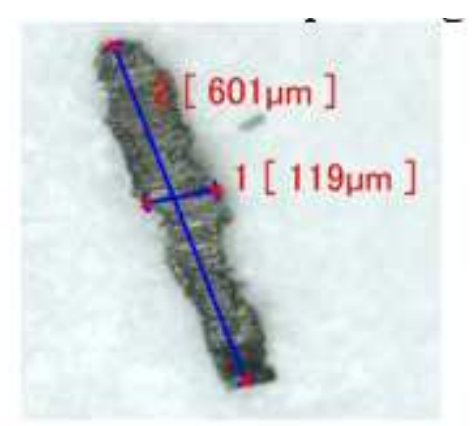

Figure 4

Strip chip

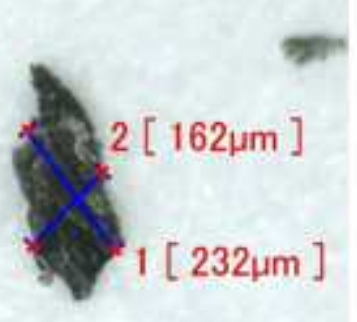

Figure 5

Microcircular chip

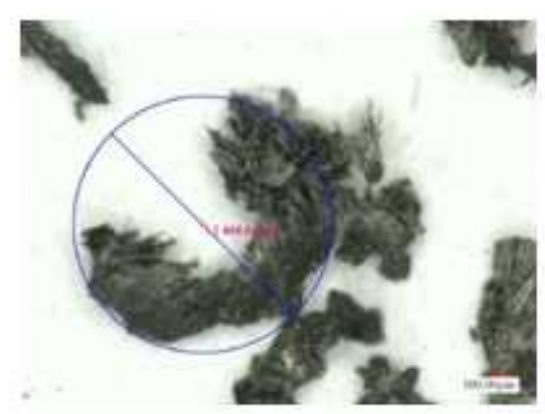

Figure 6

C chip

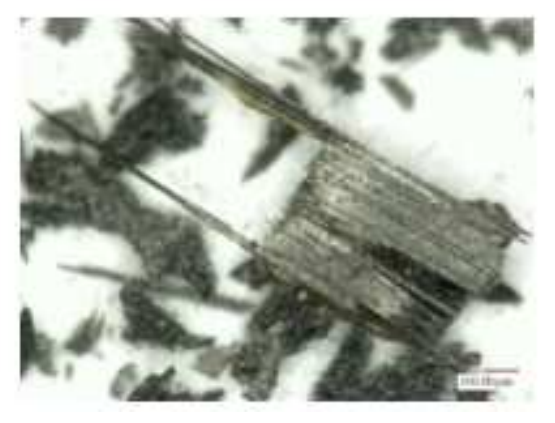

Figure 7 


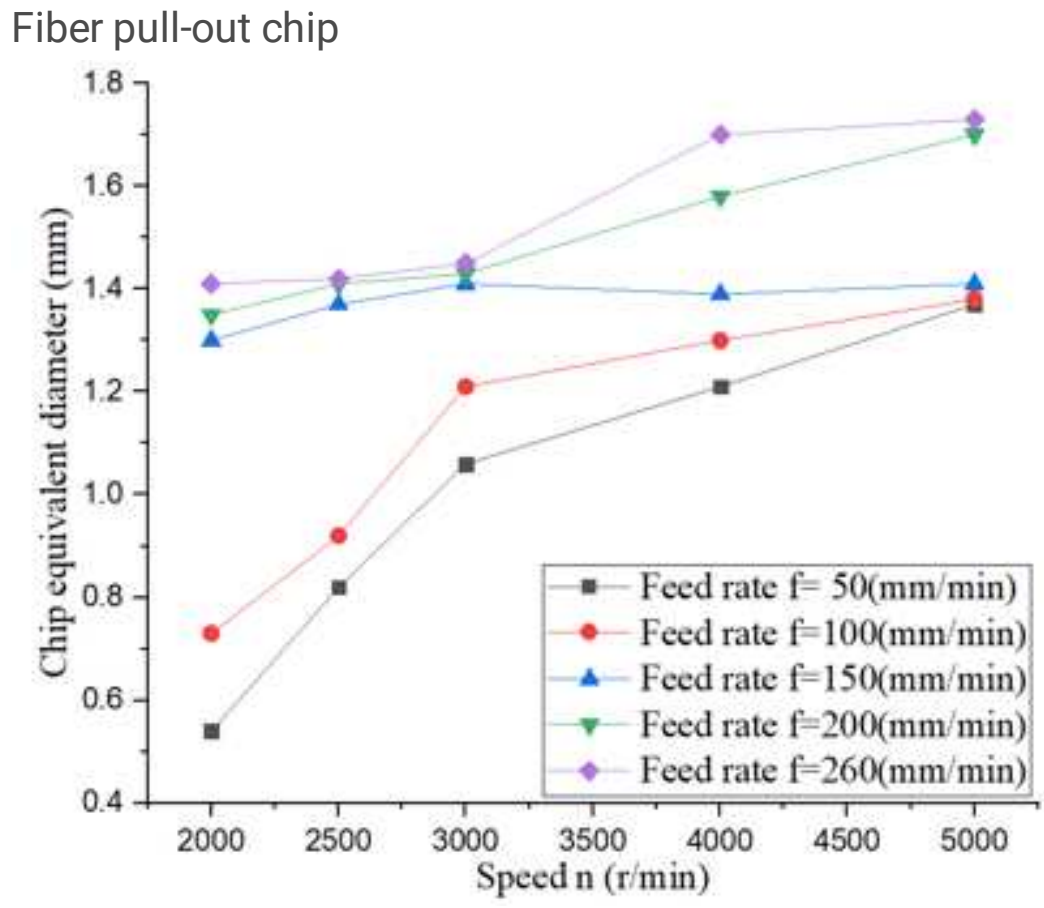

Figure 8

Relation curve of rotation, feed rate and chip diameter

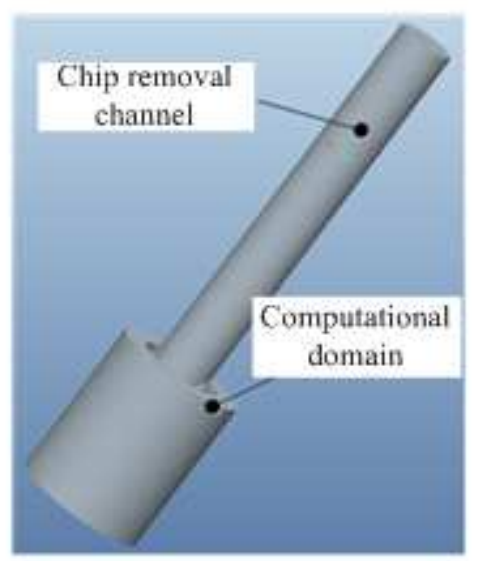

Figure 9

Chip removal fluid domain model 


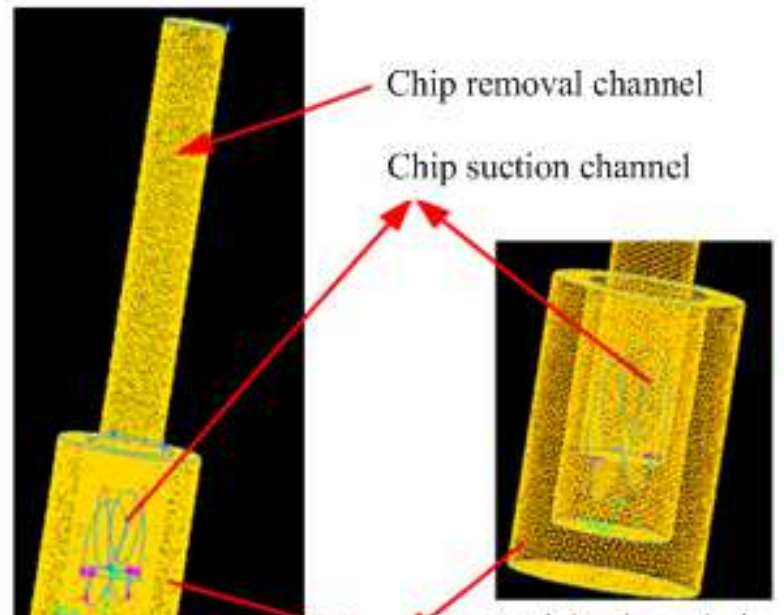

Partial enlarged view

Computational domain

Figure 10

Grid of inner flow channel and fluid domain

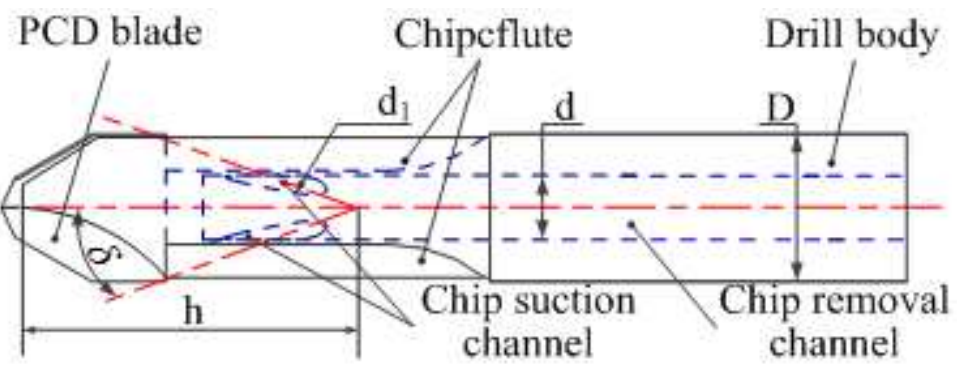

Figure 11

Drill bit inner channel structure 


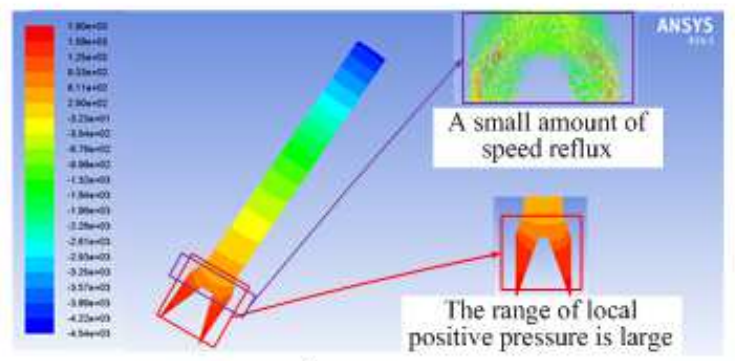

a) $h=14 \mathrm{~mm}$

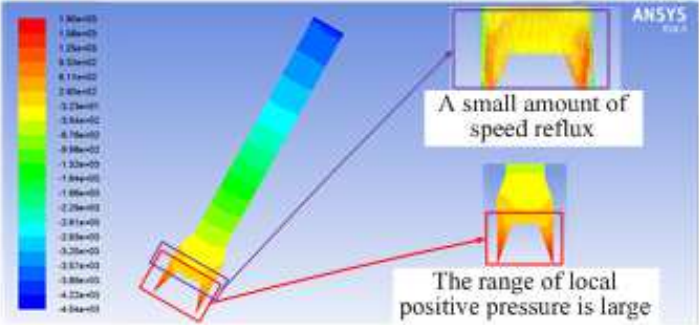

c) $h=16 \mathrm{~mm}$

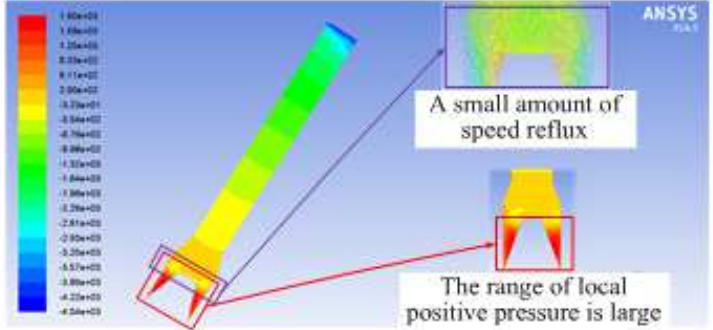

b) $h=15 \mathrm{~mm}$

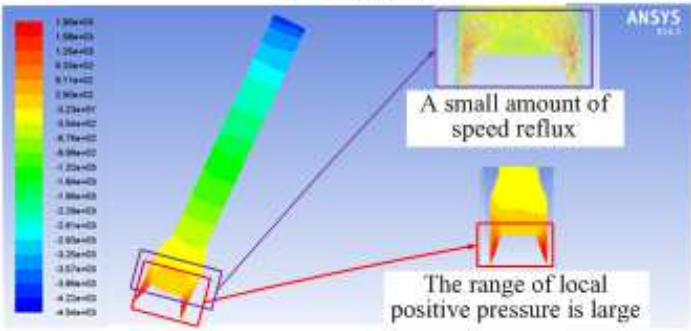

d) $h=17 \mathrm{~mm}$

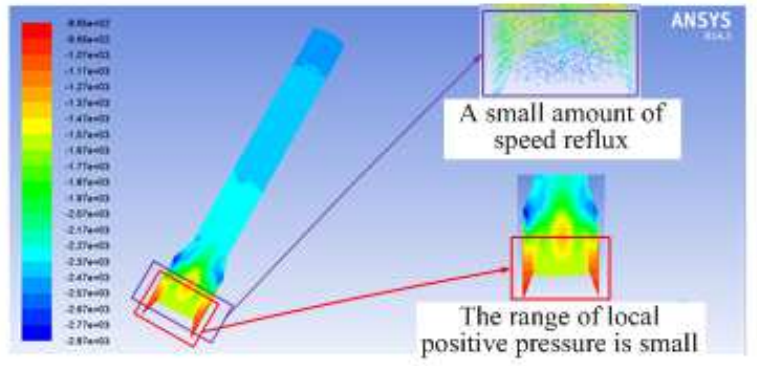

e) $h=18 \mathrm{~mm}$

Figure 12

Simulation analysis of the influence of the center distance of the runner on the chip removal effect of the runner 


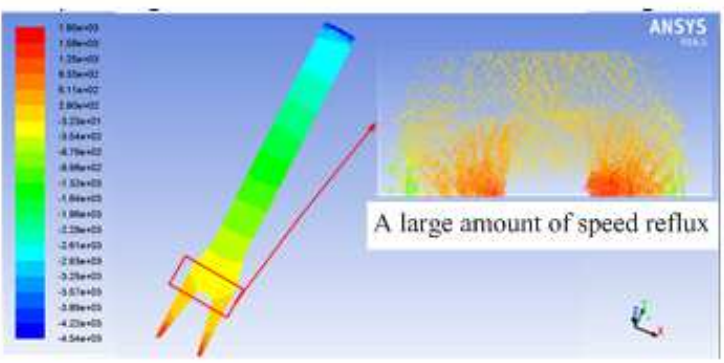

a) $\delta=12^{\circ}$

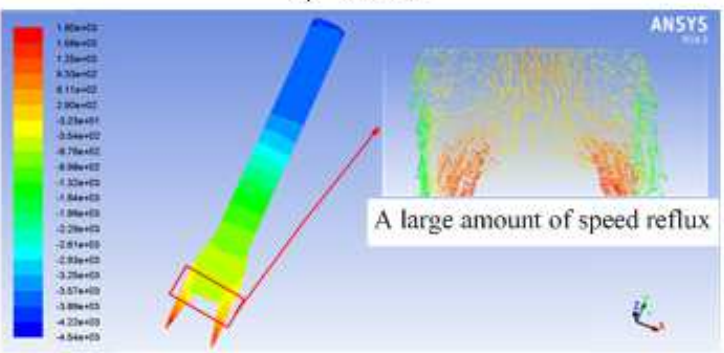

c) $\delta=16^{\circ}$

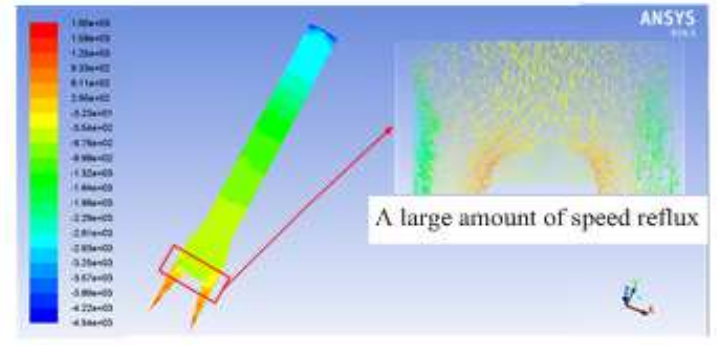

b) $\delta=14^{\circ}$

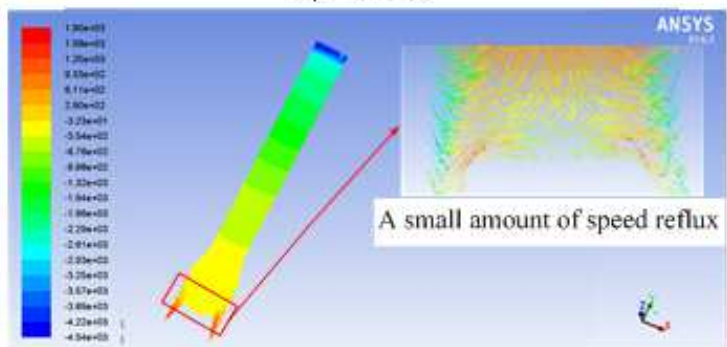

d) $\delta=18^{\circ}$

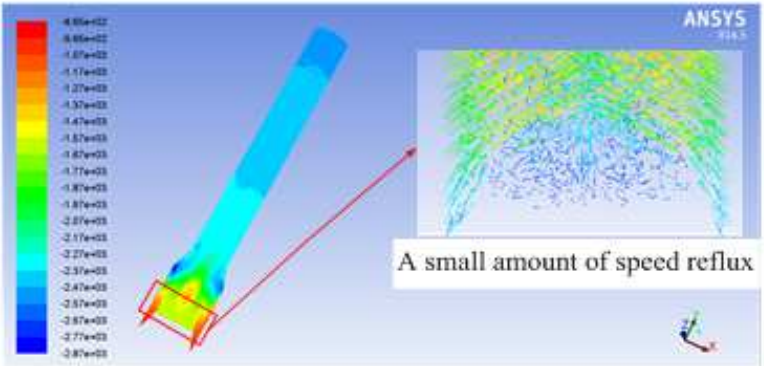

e) $\delta=20^{\circ}$

\section{Figure 13}

Simulation analysis of the influence of the center distance of the runner on the chip removal effect of the runner 


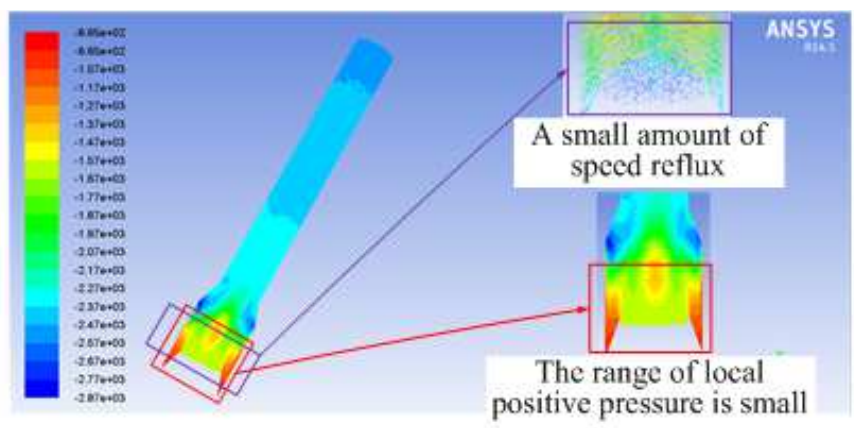

a) Circular

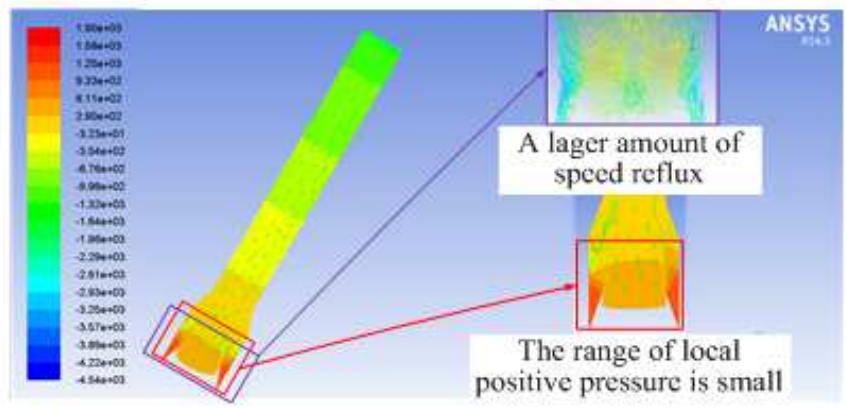

b) Ellipse

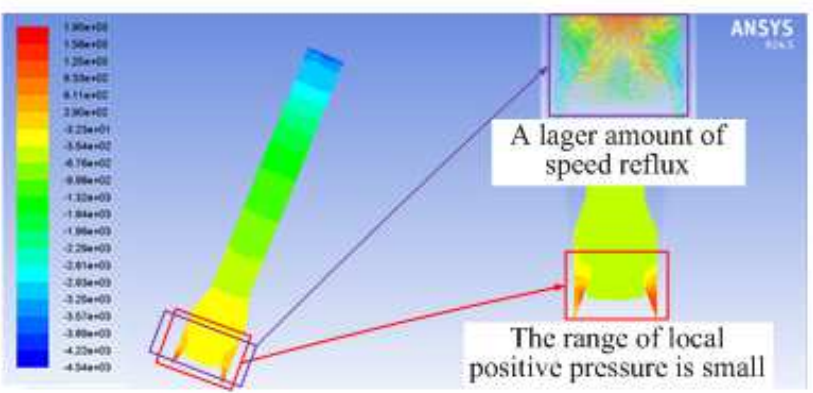

c) Square

\section{Figure 14}

Simulation analysis of the influence of the shape of the flow channel on the chip removal effect of the flow channel

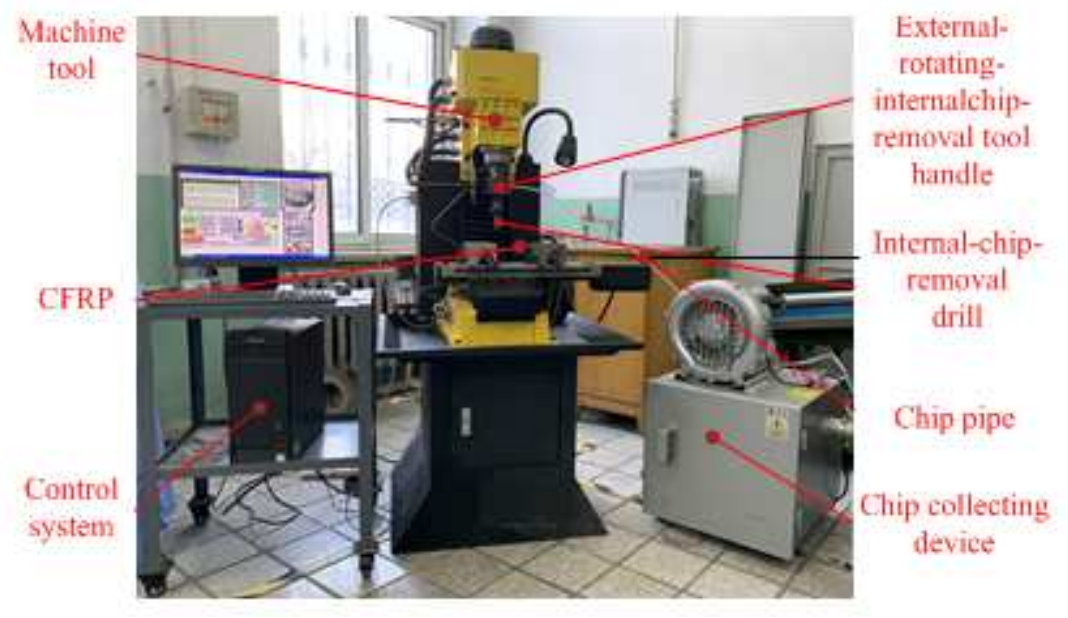

Figure 15

CFRP chip removing test stand

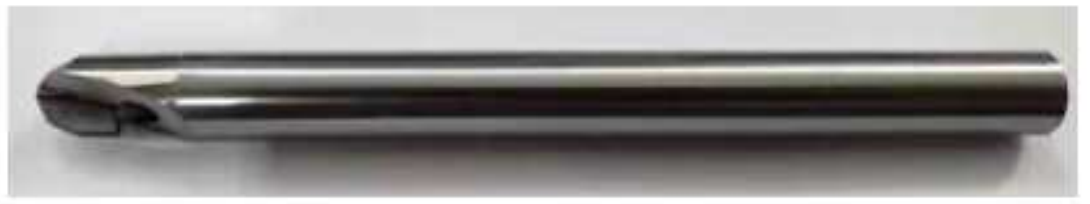

Figure 16 
PCD inner chip removing drill 